\title{
Intraocular pressure and central visual field of normal tension glaucoma
}

\author{
Makoto Araie, Mariko Kitazawa, Nobuyuki Koseki
}

\begin{abstract}
Aim-To study whether damage in the central $30^{\circ}$ field of normal tension glaucoma (NTG) is relatively heterogeneous or homogeneous with respect to intraocular pressure (IOP) related damage. Methods-Using the results of Humphrey perimeter examinations, the central $30^{\circ}$ field was divided into four subfields; superior and inferior hemifields excluding the caecocentral field (30-2 program) and superior and inferior $10^{\circ}$ hemifields (10-2 program). In 103 NTG cases, the intraindividual bilateral difference in the mean of total deviations (mean TD) in the four subfields was analysed by multiple linear regression to correct the effects of factors other than IOP. Explanatory variables were the intraindividual bilateral difference in the mean of clinic IOP $\left(\right.$ IOP $\left._{\text {mean }}\right)$, that in the ratio of area of peripapillary atrophy corresponding to each subfield to disc area, and that in myopic refraction.

Results-The intraindividual bilateral difference in the mean TD was significantly and negatively correlated with that in IOP $_{\text {mean }}$ in three of the above four subfields $(p<0.005)$ and correlation tended to be negative $(p=0.07)$ in the superior $10^{\circ}$ hemifield.

Conclusions-Diffuse IOP related damage was suggested in the central $30^{\circ}$ field of NTG; greater extent of the damage in the above four subfields was correlated with higher mean IOP. The present findings may have clinical implications. (Br f Ophthalmol 1997;81:852-856)
\end{abstract}

Normal tension glaucoma (NTG) is clinically defined as a variety of primary open angle glaucoma (POAG) of which clinical features are very similar to those of POAG, except that intraocular pressure (IOP) is consistently within normal limits. ${ }^{12}$ Prevalence of NTG is not low, accounting for one third to one half of open angle glaucoma in the west and two thirds among Japanese at the time of screening. ${ }^{3-7}$ Progression of visual field damage is seen in nearly half of NTG patients at 5 year follow up. ${ }^{8-12}$ Thus, treatment of NTG is of practical importance in clinical ophthalmology.

The IOP has also been suggested to be one of the factors contributing to progression of visual field damage in NTG, ${ }^{13}{ }^{14}$ and the intraindividual bilateral difference in the mean deviation (MD), an index of overall visual field damage in the central $30^{\circ}$ visual field, is reported to be significantly correlated with the intraindividual bilateral difference in the IOP. ${ }^{15}{ }^{16}$ It has been suggested that there are two types of the pattern visual field damage in open angle glaucoma: a relatively localised and putatively less IOP dependent type and a relatively diffuse and putatively more IOP dependent type. ${ }^{17-21}$ Comparison of visual field damage between NTG and POAG or high tension glaucoma (HTG) eyes demonstrated that for a given amount of the overall visual field damage, an area just nasal superior to the fixation was significantly more depressed in NTG eyes, while the lower centrocaecal field was significantly more depressed in HTG eyes. ${ }^{22-24}$ Visual field damage is reportedly more frequent in the inferior field, ${ }^{25}$ or more severe in the inferior arcuate area ${ }^{23}$ in NTG eyes than in POAG eyes. POAG patients with diabetes mellitus are reported to be more likely to develop visual field damage in the inferior field, suggesting that factors other than IOP, such as vascular insufficiency, may be relatively more involved in the damage in the inferior field. ${ }^{26} 27$ According to these previous findings, there might be relative heterogeneity with respect to IOP related damage in the visual field of open angle glaucoma. However, the information obtained from the above studies is limited, since the IOP was correlated only to overall damage over the whole central $30^{\circ}$ field..$^{15} 162829$ In addition, the influence of other ocular or systemic factors which may also correlate with the visual field damage was not corrected. ${ }^{15}{ }^{16}$ 22-29 Information on this heterogeneity, if any, may be of use in managing NTG. For example, given NTG patients whose visual field damage show progression in some area of the visual field, one may ask how significantly an IOP related mechanism contributes to the damage encountered and which patients preferentially require surgical ocular hypotensive therapy that may have a beneficial effect on further progression, ${ }^{13}{ }^{14} 30$ but not without risk of complications. ${ }^{30-32}$

One of the simplest ways to minimise the effects of systemic factors and highlight those of local ocular factors such as the IOP on visual field damage is to study the relation between the intraindividual bilateral differences in visual field damage and those in ocular factors. In an attempt to study whether damage in the central $30^{\circ}$ field of NTG is relatively heterogeneous or homogeneous with respect to the IOP related damage, we divided the whole central $30^{\circ}$ field into four subfields; the superior and inferior central $10^{\circ}$ hemifields, and the superior and inferior $30^{\circ}$ hemifields excluding the 
caecocentral field. The difference in the visual field performance in each subfield between the two eyes of NTG patients was correlated with that in the IOP. In doing so, the possible effects of area of peripapillary atrophy ${ }^{10123334}$ and myopic refraction, ${ }^{10}{ }^{35}$ and other ocular factors which may correlate with or influence the visual field damage in NTG, were corrected to highlight that of IOP by multiple regression analysis.

\section{Subjects and methods \\ SUBJECTS}

Among NTG patients who first visited the glaucoma clinic, department of ophthalmology, University of Tokyo School of Medicine in 1987 or later, those who met the following criteria in both eyes were included: (1) best corrected visual acuity of 0.8 or better; (2) clear ocular media without any clinically significant cataract upon biomicroscopic examination; (3) pupillary diameter of at least $3 \mathrm{~mm}$ or greater at the time of visual field examination and reliable examination both on the Humphrey 30-2 and 10-2 programs (fixation loss $<20 \%$, false negative or positive responses $<33 \%$ ); (4) no chorioretinal degeneration in the posterior fundus corresponding to the central $30^{\circ}$ visual field except for peripapillary chorioretinal atrophy or no peripapillary chorioretinal atrophy extending into the retinal area corresponding to the central $10^{\circ}$ visual field; and (5) patients who had been followed without any medication for at least 1 year. Only the results of examination with the $30-2$ or $10-2$ program which were obtained before the beginning of the therapy, if indicated, were included in the analysis. NTG was diagnosed according to the following criteria: unoccludable normal open angle, glaucomatous optic nerve head damage with a corresponding visual field damage, maximum IOP of $21 \mathrm{~mm} \mathrm{Hg}$ or lower during clinical follow up including 24 hour IOP fluctuation, no other ocular abnormalities or history of other ocular disease, no rhinological or neurosurgical disorders, and no history of massive bleeding or haemodynamic crisis. Patients who subjec-

Table 1 Ocular data of 103 patients (206 eyes) whose results of the 30-2 program were used for analysis

\begin{tabular}{llll}
\hline & All eyes & Right eyes & Left eyes \\
\hline Refraction (dioptres) & $-2.3(0.2)$ & $-2.4(0.3)$ & $-2.3(0.3)$ \\
IOP (mm Hg) & $15.4(0.1)$ & $15.3(0.2)$ & $15.4(0.2)$ \\
PPA/D $\mathrm{D}^{\star}$ & $0.44(0.03)$ & $0.40(0.04)$ & $0.48(0.05)$ \\
Mean deviation (dB) & $-7.32(0.44)$ & $-6.71(0.59)$ & $-7.94(0.64)$
\end{tabular}

Figures are mean (SE). ${ }^{\star}$ Ratio of area of peripapillary atrophy to disc area. No significant bilateral difference was seen in any of the above items.

Table 2 Ocular data of 97 patients (194 eyes) whose results of the 10-2 program were used for analysis

\begin{tabular}{llll}
\hline & All eyes & Right eyes & Left eyes \\
\hline Refraction (dioptres) & $-2.4(0.2)$ & $-2.4(0.3)$ & $-2.3(0.3)$ \\
IOP (mm Hg) & $15.3(0.1)$ & $15.3(0.2)$ & $15.3(0.2)$ \\
PPA/D ${ }^{\star}$ & $0.27(0.02)$ & $0.24(0.03)$ & $0.29(0.03)$ \\
Mean deviation (dB) & $-7.08(0.44)$ & $-6.58(0.60)$ & $-7.58(0.63)$ \\
Mean total deviation (dB)† & $-5.55(0.46)$ & $-5.48(0.63)$ & $-5.61(0.67)$ \\
\hline
\end{tabular}

Figures are mean (SE). ${ }^{\star}$ Ratio of area of peripapillary atrophy between 10:30 and 7:30 o'clock portions to disc area. †Mean of total deviations of 68 test points of the 10-2 program. No significant bilateral difference was seen in any of the above items. tively complained of central vision disturbances upon their first visits to the clinic or those under concurrent systemic medications such as $\beta$ blockers which may influence the IOP were excluded from the clinical diagnosis of NTG.

Results of the 30-2 and 10-2 programs of the Humphrey visual field analyser from both eyes of 97 NTG patients were analysed in the present study. Examination with the 30-2 and 10-2 programs had been carried out at intervals of less than 3 months. In addition, results of the 30-2 program from both eyes of six NTG patients who met the above criteria were available and they were pooled with those from the above 97 patients. The mean IOP $\left(\mathrm{IOP}_{\text {mean }}\right)$ was calculated by averaging six to 12 IOP recordings obtained at the outpatient clinic during the 1 year period wherein no ocular hypotensive therapy was given. The visual field examination of which results were included in the present analysis, had usually been carried out in the latter half of the 1 year period. Refractive error was expressed as spherical equivalent dioptres. Evaluation of area of peripapillary chorioretinal atrophy (PPA) was carried out as follows by two masked investigators and the results obtained by the two were averaged. Paper prints of the stereoscopic disc photograph were made at a magnification of $1: 10$, and the disc margin and zone $\beta^{33}$ were carefully traced on a uniform weight tracing paper, while simultaneously and carefully observing the corresponding stereoscopic photograph. Then, while viewing the stereoscopic photograph of the relevant eye under lower magnification and using the foveola and course of the retinal nerve fibre as references, the 9 and 3 o'clock portions of the disc margin were determined. Using the determined 9 and 3 o'clock portions, the 7:30 and 10:30 portions were also determined. The relative size of PPA was expressed as the ratio of the zone $\beta$ and zone $\alpha^{33}$ to that of the whole disc (PPA/D). Background data on the patients and eyes are summarised in Tables 1 and 2 .

\section{METHOD OF DATA ANALYSIS}

The intraindividual bilateral difference in the visual field performance obtained in the four subfields described below was analysed by multiple linear regression analysis (sAs, Release 6.08), using the intraindividual bilateral differences in the IOP, PPA/D, and refraction as explanatory variables.

\section{Result of 30-2 program}

The difference in the mean values of total deviations (TDs) in the superior hemifield excluding the caecocentral field (Fig 1) of the right eye minus the left eye $\left(\Delta M T D_{\text {sup }}\right)$ or the difference in the mean values of TDs in the inferior hemifield excluding the caecocentral field (Fig 1) of the right eye minus the left eye $\left(\Delta \mathrm{MTD}_{\text {inf }}\right)$ were analysed. Explanatory variables were the difference in the $\mathrm{IOP}_{\text {mean }}$ values of the right minus the left eye $\left(\Delta \mathrm{IOP} P_{\text {mean }}\right)$, the difference in the refractive error from the right eye minus the left eye ( $\Delta$ Ref), and the difference in the PPA/D of the right eye minus 


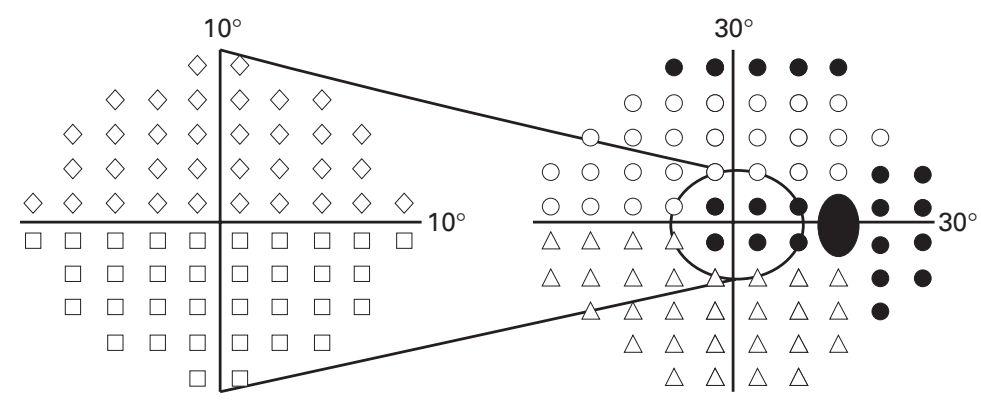

Humphrey central 10-2 program

Humphrey central 30-2 program

Figure 1 Distribution of test points presently used. Open rhombi are test points for central $10^{\circ}$ superior hemifield, open squares those for central $10^{\circ}$ inferior hemifield, open circles those for superior hemifield excluding caecocentral field, and open triangles those for inferior hemifield excluding caecocentral field. Closed squares and circles are those excluded from the present analysis.
Table 3 Multiple regression analysis of $\triangle M T D_{\text {sup }}$

\begin{tabular}{lll}
\hline Regression coefficient & Estimate $(S E)$ & $p$ Value \\
\hline $\mathrm{a}_{1}\left(\Delta \mathrm{IOP}_{\text {mean }}\right)$ & $-2.949(0.977)$ & 0.0032 \\
$\mathrm{a}_{2}(\Delta \mathrm{Ref})$ & $1.437(0.767)$ & 0.0637 \\
$\mathrm{a}_{3}(\Delta \mathrm{PPAs} / \mathrm{D})$ & $0.166(2.058)$ & 0.9359 \\
$\mathrm{a}_{4}$ & $-0.454(0.842)$ & 0.5906 \\
\hline
\end{tabular}

$\mathrm{R}$ for regression was $0.366(\mathrm{p}=0.0025)$. For explanation of $\Delta \mathrm{MTD}_{\text {sup }}, \Delta \mathrm{IOP}_{\text {mean }}, \Delta \mathrm{Ref}$, and $\Delta \mathrm{PPAs} / \mathrm{D}$, see text. $\mathrm{a}_{1}, \mathrm{a}_{2}$, and $\mathrm{a}_{3}$ are regression coefficients for $\Delta \mathrm{IOP}_{\text {mean }}, \Delta$ Ref, and $\triangle \mathrm{PPAs} / \mathrm{D}$, respectively, and $\mathrm{a}_{4}$ regression constant.

Table 4 Multiple regression analysis of $\triangle M T D_{i n f}$

\begin{tabular}{lll}
\hline Regression coefficient & Estimate $(S E)$ & p Value \\
\hline $\mathrm{a}_{1}\left(\Delta \mathrm{IOP}_{\text {mean }}\right)$ & $-3.082(0.885)$ & 0.0007 \\
$\mathrm{a}_{2}(\Delta \mathrm{Ref})$ & $-0.287(0.694)$ & 0.6798 \\
$\mathrm{a}_{3}(\Delta \mathrm{PPAi} / \mathrm{D})$ & $-5.629(1.863)$ & 0.0032 \\
$\mathrm{a}_{4}$ & $1.375(0.762)$ & 0.0742 \\
\hline
\end{tabular}

$\mathrm{R}$ for regression was $0.441(\mathrm{p}=0.0001)$. For explanation of $\Delta \mathrm{MTD}_{\text {inf }}, \Delta \mathrm{IOP}_{\text {mean }}, \Delta$ Ref, and $\triangle \mathrm{PPAs} / \mathrm{D}$, see text. $\mathrm{a}_{1}, \mathrm{a}_{2}$, and $\mathrm{a}_{3}$ are regression coefficients for $\Delta \mathrm{IOP}_{\text {mean }}, \Delta \mathrm{Ref}$, and $\Delta \mathrm{PPA} / \mathrm{D}$, respectively, and $\mathrm{a}_{4}$ regression constant.

( of Wirtshafter et al, ${ }^{36}$ it was assumed that the majority of retinal nerve fibres from the above superior arcuate field pass between the 10:30 and 3 o'clock portions of the disc margin. Thus, where that $\triangle \mathrm{MTD}_{\text {sup }}$ was analysed, the PPA area between the 10:30 and 3 o'clock portions was used $(\triangle P P A s / D)$, while that between the 3 and 7:30 o'clock portions was used for analysis of $\triangle \mathrm{MTD}_{\text {inf }}(\triangle \mathrm{PPAi} / \mathrm{D})$. Formulas used for multiple linear regression were:

$$
\begin{gathered}
\Delta \mathrm{MTD}_{\text {sup }}=\mathrm{a}_{1}\left(\Delta \mathrm{IOP}_{\text {mean }}\right)+\mathrm{a}_{2}(\Delta \mathrm{Ref})+ \\
\mathrm{a}_{3}(\Delta \mathrm{PPAs} / \mathrm{D})+\mathrm{a}_{4} \\
\text { or } \Delta \mathrm{MTD}_{\text {inf }}=\mathrm{a}_{1}\left(\Delta \mathrm{IOP}_{\text {mean }}\right)+\mathrm{a}_{2}(\Delta \mathrm{Ref})+ \\
\mathrm{a}_{3}(\Delta \mathrm{PPA} / \mathrm{D})+\mathrm{a}_{4}
\end{gathered}
$$

where $a_{1}, a_{2}$, and $a_{3}$ are regression coefficients and $\mathrm{a}_{4}$ is a regression constant.

\section{Result of 10-2 program}

The difference in the mean values of TDs in the superior central $10^{\circ}$ hemifield of the right eye minus the left eye $\left(\Delta M T D_{10, \text { sup }}\right)$ or the difference in the mean values of TDs in the inferior central $10^{\circ}$ hemifield of the right eye minus the left eye $\left(\Delta M T D_{10, \text { inf }}\right)$ were analysed. Explanatory variables were the $\Delta \mathrm{IOP}_{\text {mean }}, \Delta$ Ref, and $\triangle P P A / D$. Where that $\triangle \mathrm{MTD}_{10 \text {, sup }}$ was analysed, $\triangle \mathrm{PPA} / \mathrm{D}$ using the PPA area between the 9 and 10:30 o'clock portions ( $\triangle \mathrm{PPAc}, \mathrm{s} / \mathrm{D})$ was used, while $\triangle \mathrm{MTD}_{10, \mathrm{inf}}$ was analysed using the PPA between the 7:30 and 9 o'clock portions ( $\triangle \mathrm{PPAc}, \mathrm{i} / \mathrm{D})$.

Formulas used for multiple linear regression were:

$$
\begin{gathered}
\Delta \mathrm{MTD}_{10, \text { sup }}=\mathrm{a}_{1}\left(\Delta \mathrm{IOP}_{\text {mean }}\right)+\mathrm{a}_{2}(\Delta \mathrm{Ref})+ \\
\mathrm{a}_{3}(\Delta \mathrm{PPAc}, \mathrm{s} / \mathrm{D})+\mathrm{a}_{4} \\
\text { or } \Delta \mathrm{MTD}_{10, \text { inf }}=\mathrm{a}_{1}\left(\Delta \mathrm{IOP}_{\text {mean }}\right)+\mathrm{a}_{2}(\Delta \mathrm{Ref})+ \\
\mathrm{a}_{3}(\Delta \mathrm{PPAc}, \mathrm{i} / \mathrm{D})+\mathrm{a}_{4} \quad(2)
\end{gathered}
$$

where $a_{1}, a_{2}$, and $a_{3}$ are regression coefficients and $\mathrm{a}_{4}$ is a regression constant.

\section{Results}

Results of multiple regression analysis are summarised in Tables 3-6. The intraindividual bilateral difference in the mean values of TDs in the superior hemifield excluding the caecocentral field, that in the inferior hemifield excluding the caecocentral field, and that in the inferior central $10^{\circ}$ hemifield (Fig 1) showed significant negative correlation with the intraindividual bilateral difference in the $\mathrm{IOP}_{\text {mean }}$
Table 5 Multiple regression analysis of $\triangle M T D_{10, \text { sup }}$

\begin{tabular}{lll}
\hline Regression coefficient & Estimate $(S E)$ & p Value \\
\hline $\mathrm{a}_{1}\left(\Delta \mathrm{IOP}_{\text {mean }}\right)$ & $-2.467(1.352)$ & 0.0713 \\
$\mathrm{a}_{2}(\Delta \mathrm{Ref})$ & $1.354(1.046)$ & 0.1987 \\
$\mathrm{a}_{3}(\Delta \mathrm{PPAc}, \mathrm{s} / \mathrm{D})$ & $-9.451(4.825)$ & 0.0532 \\
$\mathrm{a}_{4}$ & $0.076(1.159)$ & 0.9480
\end{tabular}

$\mathrm{R}$ for regression was $0.358(\mathrm{p}=0.0051)$. For explanation of $\Delta \mathrm{MTD}_{10 \text {, sup }}, \Delta \mathrm{IOP}_{\text {mean }}, \Delta$ Ref, and $\Delta \mathrm{PPAc}, \mathrm{s} / \mathrm{D}$, see text. $\mathrm{a}_{1}, \mathrm{a}_{2}$, and $\mathrm{a}_{3}$ are regression coefficients for $\Delta \mathrm{IOP}_{\text {mean }}, \Delta \mathrm{Ref}$, and $\triangle \mathrm{PPAc}, \mathrm{s} / \mathrm{D}$, respectively, and $\mathrm{a}_{4}$ regression constant.

Table 6 Multiple regression analysis of $\triangle M T D_{10, \text { inf }}$

\begin{tabular}{lll}
\hline Regression coefficient & Estimate $(S E)$ & p Value \\
\hline $\mathrm{a}_{1}\left(\Delta \mathrm{IOP} \mathrm{P}_{\text {mean }}\right)$ & $-2.318(0.825)$ & 0.0060 \\
$\left.\mathrm{a}_{2}(\Delta \mathrm{Ref}) \mathrm{ic}, \mathrm{D}\right)$ & $0.914(0.638)$ & 0.1557 \\
$\mathrm{a}_{3}(\Delta \mathrm{PPAc})$ & $-6.311(2.945)$ & 0.0347 \\
$\mathrm{a}_{4}$ & $0.100(0.708)$ & 0.8882 \\
\hline
\end{tabular}

$\mathrm{R}$ for regression was $0.430(\mathrm{p}=0.0003)$. For explanation of $\Delta \mathrm{MTD}_{10, \text { inf }}, \Delta \mathrm{IOP}_{\text {mean }}, \Delta$ Ref, and $\Delta \mathrm{PPAc}, \mathrm{i} / \mathrm{D}$, see text. $\mathrm{a}_{1}, \mathrm{a}_{2}$, and $\mathrm{a}_{3}$ are regression coefficients for $\Delta \mathrm{IOP}_{\text {mean }}, \Delta$ Ref and $\Delta \mathrm{PPAc}, \mathrm{i} / \mathrm{D}$, respectively, and $\mathrm{a}_{4}$ regression constant.

(Tables 3, 4, and 6). These findings suggested that greater extent of the averaged damage in these three subfields was correlated with higher mean IOP in these NTG subjects. In the superior central $10^{\circ}$ hemifield, the intraindividual bilateral difference in the mean values of TDs tended to be negatively correlated with the intraindividual bilateral difference in the $\operatorname{IOP}_{\text {mean }}(p=0.0713)$ (Table 5), suggesting that in this subfield there tends to be a similar correlation between the extent of averaged damage and mean IOP as in the above three subfields.

The intraindividual bilateral difference in the mean values of TDs in the inferior hemifield excluding the caecocentral field and that in the inferior central $10^{\circ}$ hemifield showed significant negative correlation with the intraindividual bilateral difference in the PPAi/D and PPAc, $\mathrm{i} / \mathrm{D}$, respectively (Tables 4 and 6$)$. That in the superior central $10^{\circ}$ hemifield (Fig 1) tended to be negatively correlated with the intraindividual bilateral difference in the PPAc,s/D $(p=0.0532)$ (Table 5). These findings suggested that the greater extent of the averaged damage in these three subfields was correlated with a greater area of peripapillary 
atrophy. On the other hand, no such correlation was found in the superior hemifield excluding the caecocentral field (Table 3 ).

\section{Discussion}

In the present study, the relation of the IOP and visual field damage in four subfields in NTG patients was studied by multiple linear regression analysis, using intraindividual bilateral difference in the damage in the subfield as a dependent variable and that in the IOP, the area of PPA, and refraction as explanatory variables. The explanatory variables other than IOP have also been suggested to influence the progression of NTG. ${ }^{10} 123435$ When intraindividual bilateral difference in the visual field performance is studied in a population, interocular differences because of a fatigue effect in the questioned population must be minimised. In our glaucoma patients whose visual fields were thought to be reliable and suited for data analysis, laterality of the eye first examined is usually alternated at each testing and some rest is inserted between the first and second eye examination. In about half of the total pairs of visual fields presently used, the right eye was examined first, and the left eye in the other half. Thus, it seems unlikely that interocular difference as a result of the order of examination exerted a significant influence on the result of analysis in the present study wherein about 100 NTG cases were analysed en bloc.

We previously reported that mean of the IOPs recorded at the outpatient clinic in NTG patients had high correlation with the mean or peak of the IOPs recorded over a 24 hour period. ${ }^{37}$ According to this result, we averaged the IOP recordings over a 1 year period where patients received no ocular hypotensive therapy and adopted the average, $\mathrm{IOP}_{\text {mean }}$, as the value summarising the IOP status of the subject eye. This $\mathrm{IOP}_{\text {mean }}$ is statistically much more robust than the IOP measured during the 24 hour IOP phasing which was carried out only once before establishing clinical diagnosis of NTG. In glaucoma including NTG, an area of peripapillary atrophy (PPA) is known to correlate with the visual field damage, ${ }^{33} 3438$ but not with IOP. ${ }^{39}$ Further, according to Heijl et $a l{ }^{38}$ it is correlated with perimetric damage in the corresponding visual field quadrant. Thus, it is important to correct for the possible effect of PPA in analysing the effect of IOP on visual field damage. In correcting for the effect of PPA, pointwise analysis is disadvantageous, since it is difficult to determine the area of PPA corresponding to each test point of the 30-2 or 10-2 program. Although putative test points of IOP related damage may be swamped by others with non-IOP related damage in the subfield, a relatively large subfield - that is, a relatively large cluster of test points, has advantages; it becomes easier to determine the area of PPA corresponding to the questioned subfield, and an average of thresholds in such a cluster is less affected by test-retest variability than the result at each test point.

The results of analysis suggested that averaged visual field damage is statistically significantly correlated with the IOP in the supe- rior and inferior $30^{\circ}$ hemifields, excluding the caecocentral field and inferior central $10^{\circ}$ hemifield. In the superior central $10^{\circ}$ hemifield, correlation between the IOP and the visual field damage tended to be significant $(p=0.0713)$ and the estimated regression coefficient was in a similar range to those in the other three subfields. Since this area is often affected in both eyes in glaucoma regardless of interocular IOP difference, it might be difficult to detect the effect of IOP sensitively. The superior and inferior portions of the lamina cribrosa have less structural support than the nasal or temporal portions, ${ }^{40}$ and POAG eyes usually develop visual field damage in the superior or inferior arcuate field in the early stage. ${ }^{41}$ These findings suggest that damage in the superior or inferior arcuate field is relatively more IOP dependent. The present finding suggests that this is also the case in NTG, providing additional evidence that the IOP is one of the risk factors in the development of NTG. The visual field proximal to the fixation is probably the most important for proper vision and this area of the visual field is of clinical concern especially in NTG, since visual field damage is reportedly more likely to be deeper and closer to the fixation in NTG than in POAG. ${ }^{822} 24{ }^{42}{ }^{43}$ At the present time, reduction of the IOP to an ultra low level by filtering surgery is the only treatment modality which was reportedly effective in dampening or even halting the progression of visual field damage in NTG. ${ }^{13}{ }^{14}{ }^{30}$ Although prospective clinical trials should address the effect of ocular hypotensive therapy on the visual field damage in NTG, the present result is not incompatible with the above previous findings. The inferior caecocentral field is usually spared until the late stages of glaucoma. ${ }^{414}$ The present finding may also suggest beneficial effects of ocular hypotensive therapy in retarding the final loss of central vision in NTG patients.

As has been described, the area of peripapillary atrophy in the glaucomatous eye is significantly correlated with intrapapillary neuroretinal rim loss and perimetric defects in the corresponding visual field quadrants, but not with the IOP. ${ }^{33} 3839$ There was also no correlation between IOP and PPA/D $(r=-0.055)$ in the present subjects. On the other hand, the correlation of peripapillary atrophy with the averaged visual field damage was significant in the two inferior subfields and tended to be significant $(p=0.0532)$ in the superior central $10^{\circ}$ hemifield, which confirmed that correlation between the peripapillary atrophy and perimetric defects also exists in NTG. ${ }^{34}$ In the superior $30^{\circ}$ hemifield excluding the caecocentral field, the averaged damage did not show correlation with peripapillary atrophy, while it showed a highly significant correlation with the IOP. According to Geijssen, ${ }^{10}$ peripapillary atrophy may represent one of local vascular risk factors, not being correlated with the IOP. ${ }^{33} 3839$ This finding may be compatible with the fact that the inferior portion of the lamina cribrosa is relatively more vulnerable to an IOP dependent damaging factor. ${ }^{40}$ 
A limiting factor of the present analysis is that the $\mathrm{R}$ value for the model was not large, being $0.36-0.44$. This is probably partly due to a relatively small right-left difference in the IOP $_{\text {mean }}$ of the present subjects; its absolute value averaged about $0.5 \mathrm{~mm} \mathrm{Hg}$. Further, it is easy to speculate that bilateral differences in visual field damage could also be influenced by other factors such as the duration of disease which could not be incorporated into the present model. The patients' age may be related to the duration of disease. However, no significant correlation was found between the intraindividual bilateral difference in $M D$ and age in the present subjects $(r=0.167, \mathrm{p}=0.090)$. Thus, the inclusion of age in the present analysis would not affect the $\mathrm{R}$ value for the model.

In summary, the present study suggested that there is relative homogeneity with respect to IOP related damage in the central $30^{\circ}$ visual field of NTG. The present finding may have clinical implications in treating patients with NTG.

1 Levene RZ. Low tension glaucoma: a critical review and new material. Surv Ophthalmol 1980;24:621-64.

2 Hitchings RA. Low tension glaucoma-its place in modern glaucoma practice. Br f Ophthalmol 1992;76:494-6.

3 Hollows FC, Graham PA. Intra-ocular pressure, glaucoma, and glaucoma suspects in a defined population. $\mathrm{Br} \mathcal{F} \mathrm{Oph}-$ thalmol 1966;50:570-86.

4 Bengtsson B. The prevalence of glaucoma. Br f Ophthalmol 1981;65:46-9.

5 Klein BE, Klein R, Sponsel WE, Franke T, Cantor LB, Martone J, et al. Prevalence of glaucoma. The Beaver Dam Eye Study. Ophthalmology 1992;99:1499-504.

6 Dielemans I, Vingerling JR, Algra D, Hofman A, Grobbee DE, de Jong PT. Primary open-angle glaucoma, intraocular pressure, and systemic blood pressure in the general elderly population. The Rotterdam Study. Ophthalmology 1995; population.

7 Shiose Y, Kitazawa Y, Tsukahara S, Akamatsu T, Mizokami K, Futa R, et al. Epidemiology of glaucoma in Japan-a nationwide glaucoma survey. Ұpn f Ophthalmol 1991;35: 133-55.

8 Glicklich RE, Steinmann WC, Spaeth GL. Visual field change in low-tension glaucoma over a five-year follow-up Ophthalmology 1989;96:316-20.

9 Noureddin BN, Poinoosawmy D, Fietzke FW, Hitchings RA. Regression analysis of visual field progression in low tension glaucoma. Br f Ophthalmol 1991;75:493-5.

10 Geijssen HC. Studies on normal pressure glaucoma. New York: Kugler, 1991:195-213.

11 Yoshikawa K, Inoue T, Inoue Y. Normal tension glaucoma the value of predictive tests. Acta Ophthalmol 1993;71:46370.

12 Araie M, Sekine M, Suzuki Y, Koseki N. Factors contributing to the progression of visual field damage in eyes with
normal tension glaucoma. Ophthalmology 1994;101:1440nor

13 Abedin S, Simmons RJ, Grant WM. Progressive low-tension glaucoma: treatment to stop glaucomatous cupping and field loss when these progress despite normal intraocular pressure. Ophthalmology 1982;89:1-6.

14 Hitchings RA, Wu J, Poinoosawmy D, McNaught A. Surgery for normal tension glaucoma. $\mathrm{Br} \mathcal{F}$ Ophthalmol 1995;79:402-6.

15 Cartwright MJ, Anderson DR. Correlation of asymmetric damage with asymmetric intraocular pressure in normal tension glaucoma (low-tension glaucoma). Arch Ophthalmol 1988;106:898-900.

16 Crichton A, Drance SM, Douglas GR, Schulzer M Unequal intraocular pressure and its relation to asymmetric visual field defects in low-tension glaucoma. Ophthalmology 1989;96:1312-4.

17 Caprioli J, Sears M, Miller JM. Patterns of early visual field loss in open-angle glaucoma. [Published erratum appears in Am f Ophthalmol 1987;104:98] Am f Ophthalmol 1987;103: 512-7.

18 Drance SM, Douglas GR, Airaksinen PJ, Schulzer M, Hitchings RA. Diffuse visual field loss in chronic open-angle and low-tension glaucoma. Am 7 Ophthalmol 987;104:577-80.

19 Chauhan BC, Drance SM, Douglas GR, Johnson CA. Visual field damage in normal-tension and high-tension glaucoma. Am f Ophthalmol 1989;108:636-42.

20 Chauhan BC, Drance SM. The influence of intraocular pressure on visual field damage in patients with normaltension and high-tension glaucoma. Invest Ophthalmol Vis Sci 1990;31:2367-72

21 Schulzer M, Drance SM, Carter CJ, Brooks DE, Douglas GR, Lau W. Biostatistical evidence for two distinct chronic open angle glaucoma populations. $\mathrm{Br} \mathcal{F}$ Ophthalmol 1990;74:196-200.

22 Araie M, Yamagami J, Suzuki Y. Visual field defects in normal-tension and high-tension glaucoma. Ophthalmology 1993:100:1808-14.

23 Araie M, Hori J, Koseki N. Comparison of visual field defects between normal-tension and primary open-angle glaucoma in the late stage of the disease. Graefes Arch Clin Exp Ophthalmol 1995;233:610-6.

24 Koseki N, Araie M, Yamagami J, Suzuki Y. Sectorization of central 10-deg visual field in open angle glaucoma. An approach for its brief evaluation. Graefes Arch Clin Exp Ophthalmology 1995;233:621-6.

25 Gramer E, Althaus G, Leydhecker W. Topography and progression of visual field damage in low tension glaucoma, open angle glaucoma and pigmentary glaucoma with the program Delta of the Octopus Perimeter 201. A clinical study. In: Greve EL, Heijl A, eds. Seventh international study. In: Greve EL, Heijl A, eds. Seventh international
visual field symposium, 1986. Dordrecht: Martinus Nijhoff/Dr W Junk, 1987;349-63. (Doc Ophthalmol Proc Ser 49.)

26 Zeiter JH, Shin DH, Baek NH. Visual field defects in diabetic patients with primary open-angle glaucoma. $A m \mathcal{F}$ Ophthalmol 1991;111:581-4.

27 Zeiter JH, Shin DH. Diabetes in primary open-angle glaucoma patients with inferior visual field defects. Graefes Arch Clin Exp Ophthalmol 1994;232:205-10.

28 Yamazaki Y, Koide C, Takahashi F, Yamada H. Diffuse nerve fiber layer loss in normal tension glaucoma. Int Ophthalmol 1992;16:247-50.

29 Yamazaki Y, Miyamoto S, Hayamizu F, Nakagami T, Koide C. The relationshiop between visual field defects and cliniC. The relationshiop between visual field defects and clini-
cal factors in normal-tension glaucoma. Acta Soc Ophthalmol fpn 1995;99:1017-21.

30 Yamamoto T, Ichien M, Suemori-Matsushita H, Kitazawa Y. Trabeculectomy for normal-tension glaucoma. Acta Soc Ophthalmol fpn 1994;98:579-83.

31 Wilson RP, Steinmann WC. Use of trabeculectomy with postoperative 5-fluorouracil in patients requiring extremely
low intraocular pressure levels to limit further glaucoma progression. Ophthalmology 1991;98:1047-52.

32 Zacharia PT, Deppermann SR, Schuman JS. Ocular hypotony after trabeculectomy with mitomycin C. Am f Ophthalmol 1993;116:314-26.

33 Jonas JB, Naumann GOH. Parapapillary chorioretinal atrophy in normal and glaucoma eyes. II Correlations. Invest Ophthalmol Vis Sci 1989;30:919-26.

34 Park KH, Tomita G, Liou SY, Kitazawa Y. Correlation between peripapillary atrophy and optic nerve damage in ormal-tension glaucoma. Ophthalmology 1996;103:1899906.

35 Perkins ES, Phelps CD. Open angle glaucoma, ocular hypertension, low-tension glaucoma and refraction. Arch Ophthalmol 1982;100:1464-7.

36 Wirtschafter JD, Becker WL, Howe JB, Younge BR. Glaucoma visual field analysis by computed profile of nerve fiber function in optic disc sectors. Ophthalmology 1982;89: 255-67.

37 Yamagami J, Araie M, Aihara M, Yamamoto S. Diurnal variation in intraocular pressure of normal-tension glaucoma eyes. Ophthalmology 1993;100:643-50.

38 Heijl A, Samander C. Peripapillary atrophy and glaucomatous visual field defects. In: Heijl A, Greve EL, eds. Sixth international visual field symposium, 1984. Dordrecht: Dr WW Junk, 1985;403-7. (Doc Ophthalmol Proc Ser 42.)

39 Jonas JB, Papastathopoulos KI. Pressure-dependent changes of the optic disk in primary open-angle glaucoma. Am F Ophthalmol 1995;119:313-7.

40 Fechtner RD, Weinreb RN. Mechanisms of optic nerve damage in primary open angle glaucoma. Surv Ophthalmol 1994;39:23-42.

41 Drance SM. Glaucomatous visual field defects. In: Ritch R, Shields MB, Krupin T, eds. The glaucomas. St Louis: CV Mosby, 1989;1:393-402.

42 Caprioli J, Spaeth GL. Comparison of visual field defects in the low-tension glaucomas with those in the high-tension glaucomas Am f Ophthalmol 1984;97:730-7.

43 Chumbley LC, Brubaker RF. Low-tension glaucoma. $A m \mathcal{F}$ Ophthalmol 1976;81:761-7.

44 Weber J, Schultze T, Ulrich $\mathrm{H}$. The visual field in advanced glaucoma. Int Ophthalmol 1989;13:47-50. 